\title{
AN INTRODUCTORY PERSPECTIVE ON THE KNOWLEDGE ENABLEMENT LANDSCAPE
}

\author{
POTENTIAL FOR HIGHER EDUCATION-THIRD \\ SECTOR ENGAGEMENT
}

\section{Ruth Albertyn \& Mabel Erasmus}

\section{INTRODUCTION}

If higher education is to play a meaningful role in society, it needs to engage with external knowledge partners. Community engagement, civic engagements and community interaction are concepts currently used internationally and in South Africa to describe this third core function of higher education institutions, practised alongside and integrated with teaching-and-learning and research. Organisations from the third sector of society, and non-profit organisations in particular, are often willing and able to be knowledge partners in higher education engagement endeavours. This landscape of the community interaction project in which universities engage is the focus of this book. In addition to this introductory chapter the book comprises the following three sections: The chapters in Part One put forward some of the main conceptual positions that guided our thinking; in Part Two the chapters specifically focus on matters pertaining directly to the third sector; and Part Three is dedicated to case studies proclaiming new approaches to knowledge enablement through higher education-third sector engagement. Our premise is that there is an essential link between enablement and knowledge creation, and the interaction between these concepts will be expounded in the chapters of this book.

The community engagement imperative in the higher education context has been well documented (Boyer 1990; Jansen 2002:507; Kraak 2004:244). Community engagement can contribute to serving the aims of social justice, equity and transformation in the historical context of South African higher education and society (Albertyn \& Daniels 2009:413-415; Petersen \& Osman 2013:4-5). The landscape of engaged activity in the South African context influences the work done in these 
sites and thus forms the backdrop of our project. There are also innate tensions that universities face because they have to function in the globalised economy with the competitive, individualised focus of knowledge economies (Gibbons et al 1994:3; James, Guile \& Unwin 2013:245). It is therefore a challenge for universities to remain relevant while retaining accountability to the local context where they practise their mission. However, what happens at the interface between higher education institutions and third sector organisations has not been explored in any depth in the South African context. The purpose of this book is to contribute to and promote dialogue on principles and practices of enablement though reciprocal knowledge sharing and collaborative building and utilisation of knowledge between the third sector of society and higher education institutions. It is our wish that by sharing contributions from both the higher education and the third sector in this book we will contribute to creating a 'buzz' in the landscape around the potential of this knowledge partnership to provide a generative space for knowledge production and innovation.

A landscape is a fusion of elements of people and places which together form an entity with specific characteristics. In this introductory chapter we explore the backdrop of this community engagement landscape where knowledge is created for mutual enablement. We argue that a common vision and mission could provide a fruitful focus in the process of community engagement.

We begin this chapter with more about the rationale behind our decision to bring together a volume of conceptual and research-based chapters on enabling knowledge through community engagement. Next we explore the community engagement context by looking at the motivation for focusing on the higher education engaged knowledge project in collaboration with external partners from the third sector of society, and more particularly non-profit organisations which constitute a large part of this sector. We then look at the purpose or the common mission of these knowledge partnerships, and finally we consider the process of mutual enablement towards achieving co-created goals. This discussion will set the stage for the chapters to follow.

\section{THE RATIONALE BEHIND THE ENABLING KNOWLEDGE COMMUNITY ENGAGEMENT INITIATIVE}

Even though the phenomenon referred to as 'community engagement' (CE) has by now evolved as a third function of higher education institutions (HEls) in South Africa (Lazarus, Erasmus, Hendricks, Nduna \& Slamat 2008:60; Hall 2010:1-2; RSA DHET 2013:39), huge gaps in this subfield still remain. Definitions of CE often 
represent attempts to capture the complexities and (political) sensitivity inherent in the concept. For example: CE is defined as "continuously negotiated collaboration and partnerships between [the HEI] and the interest groups that it interacts with, aimed at building and exchanging the knowledge, skills, expertise and resources required to develop and sustain society" (UFS 2006). We concur with the opinion expressed in the White Paper for Post-School Education and Training (RSA DHET 2013:39) that CE "has been a concept with which the South African higher education system has grappled for more than a decade". There clearly is a dire need to investigate and expand the collaborative knowledge-building activities between the following stakeholders in the broad CE endeavour: local communities; organised civil society or the third sector (non-profit organisations in particular); the HE sector (institutions, staff and students); the public (first) sector; and the private (second) sector. The authors of the chapters in this book wish to make a contribution to such an endeavour by presenting CE as a complex, crucial component of scholarly work, within HE and beyond.

We know from experience and also deduce from the literature (Thomson, SmithTolken, Naidoo \& Bringle 2008:227-228; Hall 2010:48; Bezuidenhout \& Erasmus 2013:168) that HEls in many countries largely rely on collaboration with organisations within the third sector of society as sites for academic student service placement and community-based contextual research. Furthermore, given budgetary and other resource constraints within HE and the "vastly different" ways in which universities approach community engagement, "it is likely that future funding of such initiatives in universities will be restricted to programmes linked directly to the academic programme of universities, and form part of the teaching and research function of these institutions" (RSA DHET 2013:39).

The chapter by Daniel Hammett and Daniel Vickers (with contributions from students) is an example of how thoughtful reflection on the field experiences of students provides an opportune moment to turn experiential learning into a process of knowledge enablement and knowledge transfer among students and third sector participants. However, in the South African HE sector these opportunities are not always explored. There often seems to be a limited understanding of who third sector organisations are, how they function, what challenges they face, and what forms of capacity building they might require. While staff and students from HEls are focused on the purpose of their planned activities at the NPO sites and the outcomes they wish to achieve, the voices (Alperstein 2007; Nduna 2007; Du Plessis \& Van Dyk 2013) of the NPO staff and the community members who are served by these NPOs are often less audible. Power relations in the 'knowledge society' tend to be in favour of academic 
knowledge that is perceived as being more valid and worthwhile than the knowledge that so-called laypersons in the community hold, despite the latter's many years of experience in the field. The irony is that without the NPO sector those who are most vulnerable in South African society will have no safety net where the service sector and their own local communities fail them. In terms of their social responsiveness, the higher and further education and training sector therefore needs to support NPOs more, by joining them in knowledge-based community activism, responding adequately to their training needs, influencing relevant policy implementation and playing a constructive role in community-based and participatory action research in collaboration with this sector. In the chapter by Grey Magaiza he explores community engaged scholarship as a pedagogy of possibility which is an ethically and politically justified scholarly activity that advocates for the best in the human condition.

Butin (2010:133) argues for reimagining collaborative practices and interdisciplinary inquiry, and for studying CE in its various manifestations "as a wonderfully complex and situated practice" that actually disturbs us and forces us to rethink the normal patterns of thought, belief and the very nature of scholarship. In looking at what is important to both sectors in the HE partnership and what matters to each, the knowledge creation process can be directed with positive fruifful focus on energising forces to achieve mutual benefits to both partners. This does not mean that the challenges and problems distinct in complex systems are repudiated. On the contrary, if the focus is on fruitful collaboration, then the creative tension which is characteristic of any complex system will be harnessed to provide a process and product which is innovative and of reciprocal value.

However, there are risks involved in such an enterprise. Risk is acknowledged as being an inherent part of any innovation process which implies change (Brown 2010:1215). If risk is seen as something to be avoided, the results of the knowledge process and project could be stifling, controlling and inhibited (Frick, Albertyn \& Bitzer 2014:56). The fundamental force in these kinds of controlling interactions reflects power imbalances which threaten the sustainability of projects. In her chapter Mabel Erasmus points to the political unconscious of such power imbalances in society, which necessitates the creative coordination of the ideological with the Utopian elements inherent in community engagement in order to move forward in the knowledge society.

The White Paper for Post-School Education and Training (RSA DHET 2013:39) provides a concise outline of what the manifestations or forms of CE can entail, and acknowledges its presence within the higher education sector in the following statement: 
What has emerged is that community engagement, in its various forms socially responsive research, partnerships with civil society organisations, formal learning programmes that engage students in community work as a formal part of their academic programmes, and many other formal and informal aspects of academic work - has become a part of the work of universities in South Africa.

The chapters of this book thus represent a broad variety of the possible forms of CE, often integrated with and infused into both teaching-and-learning and research, and specifically in the context of "partnerships with civil society organisations" of the third sector. The aim is to search for essential links between knowledge and enablement for the purpose of improving and deepening engagement between $\mathrm{HEl}$ and organisations of the third sector. The chapter by Elize Janse van Rensburg focuses on identifying factors that facilitate or act as barriers to enablement. She defines the concept of enablement and identifies principles which could serve as a guide for enablement in communities and emphasises the power of reciprocal knowledge sharing in a mutually enabling endeavour.

\section{THE CONTEXT OF HIGHER EDUCATION-THIRD SECTOR ENGAGEMENT}

In the 'knowledge economy' collaboration between HE and the public (first) and private (second) sectors of society is a given. According to Habib (2002:viii) the civil society sector "of which so little is known, represents the third element in the development equation". Over the years the state and the market have been subjected to rigorous study, while civil society (third sector) has remained largely under-theorised despite being considered by many as representing a bridge between the citizenry on the one hand and the state and the market on the other. The growing realisation that development (and some forms of service delivery, for that matter) cannot be realised without the participation and mobilisation of this sector has led to initiatives across the world to study civil society, specifically in its third sector manifestations. Taylor (2010:1) describes a number of noteworthy developments in the field, providing "incontrovertible" evidence that there has been "a dramatic rise in research" which is gradually moving towards the establishment of third sector research as a new field of study. However, research into this sector in the South African context is not welldeveloped and thus closer involvement and deeper engagement from the higher education sector is required. The research reported in the chapter by Deidré van Rooyen and Willem Ellis was motivated by the need for an informed understanding of the third sector by any party wanting to interact with this sector, and provides insight into co-creating developmental solutions for challenges in the South African context through constructive engagement. 
A comprehensive study of the size and scope of the non-profit sector in South Africa (Swilling \& Russell 2002) was undertaken towards the end of the previous century. This is the first ever study that could claim to describe the sector in terms of its background, scale, employment, volunteers and finances, as well as its spread across different sectors of activity. The study posed considerable difficulties to the research team, but also rendered invaluable information for policy and practice. Since the intended follow-up study that was envisaged had not materialised at the time of publication of this book and no other comprehensive studies could be found, we had to rely largely on Swilling and Russell (2002) in selecting a few pointers about the field that are relevant to our book. We subsequently discuss these in conjunction with a limited number of international resources that offer more recent insights pertaining to the role and positioning of third sector organisations in society.

Taylor (2010:1) points out that a broadly accepted way of describing the third sector is achieved by defining it with respect to five structural and operational features: it is organised, private (separate from government), self-governing, non-profit distributing and non-compulsory. According to Ridley-Duff (2008:1), the third sector consists of "organisations established by people on a voluntary basis to pursue social or community goals". Civil society organisations from this sector include NPOs, social movements, and other notions of civil society such as communitybased and faith-based organisations. Corry (2010:16) includes social enterprises, partnerships and pressure groups. The range of possible forms or manifestations is broad. On the one end of the continuum they include multinational organisations positioned within "global civil society" with the critical intent of promoting ethics that centres on "the oneness of humanity", the equality of all people and the idea that we have obligations to others that stretch beyond those that we are related to in some way or another (Taylor 2010:7). On the other end of the continuum there are survivalist, street-level organisations of every possible creed and kind. In Stephan de Beer's chapter, he looks at local neighbourhoods in the inner city of Tshwane as possible sites of engagement. He argues for a reimagination of the third sector drawing from a spirituality of abundance, exploring innovation and enterprise, and fostering practices of sustainability - which would enable optimal partnerships with local neighbourhoods and higher education institutions, hopefully resulting in more sustainable transformations.

It is possible for HEls to collaborate with any of the civil society organisations mentioned above; however, when the aim of CE is to engage more closely with the developmental spaces where grassroots struggles are taking place, university staff members often find it useful and productive to partner with organisations registered 
as NPOs. Examples are reported in the chapter by Kirna Hellmuth, who explores the contributions of the religious faith factor in faith-based NPOs and looks at ways that a partnership with higher education can contribute to management skills and knowledge for increased sustainability.

In the South African context organisations define themselves as registered NPOs by undergoing the process of being registered in terms of the Nonprofit Organisations Act 71 of 1997 . Through such registration, they qualify to access the potentially huge financial benefits to be gained through a number of other acts (Swilling \& Russell 2002:78). The term non-governmental organisations (NGOs) is often used interchangeably with NPOs. Nzimakwe (2008:90) refers to NGOs as private, selfgoverning, non-profit organisations promoting people-centred development, which are responsible to their donors and to the communities they serve. However, by being registered as an NPO, these organisations also become accountable to government and end up in the "cut-and-thrust of contemporary state NPO dynamics - both amicable and conflictual - as a dialogical struggle to define and give substantive content to the public space that has been created by law for managing state-civil society relations" (Swilling \& Russell 2002:77). The question of finance for sustainability is relevant and the chapter by Willem Ellis and Deidré van Rooyen looks at the concept of social entrepreneurship. They report the findings of their study, highlighting the challenges facing the third sector in its endeavour to adopt a social entrepreneurial approach.

Amidst the highly contentious positioning of NPOs and the dire need for the public and private sectors to take NPOs more seriously, Habib (2002:x) calls upon higher education institutions to introduce Honours or Master's teaching programmes designed primarily for the non-profit sector. More than a decade after the publication of the book by Swilling and Russell no such programme has yet been introduced in the South African HE context. This is in stark contrast to what has been happening elsewhere, especially in and from the United States, where the rise of the third sector can be illustrated by the "rapid global expansion" in academic centres and graduate degree programmes dedicated to non-profit management, voluntary organisations and philanthropy (Taylor 2010:1). One of the ideals behind the publication of this book is that it will become a useful resource in future post-school education and training programmes aimed at building capacity for the sector and stimulating further research about the intersection between higher education and NPOs in particular. Most of the other chapters in the book were produced in collaboration with or by persons from the NPO sector. We believe that valuable examples and principles of how knowledge becomes an enabler, specifically through engagement between the 
HE and the third sector, can be deduced from each of the chapters. Simultaneously, the reader will learn more about the inner workings of both HEls and NPOs.

\section{THE COMMON PURPOSE OF ENGAGEMENT INITIATIVES AIMED AT KNOWLEDGE ENABLEMENT}

To provide a unifying focus for community engagement, we propose that we need to acknowledge and explore the common mission of such projects. One of the ways to build in reciprocity and move away from discrepancies of power is to act as partners with a common mission. Carlisle (2004:559) confirms the importance of developing common meaning as a way to address differences in various sites in a system. A common vision provides the fruifful focus for the interaction between partners in a complex system. The motive of an innovative project is change towards a desired goal (Brown 2010:1212). Edwards $(2011: 33,37)$ refers to this as "common knowledge" or "common understandings", and she suggests that this is an emotional driver of activity which is identified by asking participants what matters to them. She also refers to the long-term purpose of practices (Edwards 2011:35). Engeström (2001:134) refers to the common mission as the "object of activity" in his proposed activity theory, which is the objective or motive for the activity in the system.

An engaged university can contribute to change in society through knowledge enablement. Contemplating what the role of knowledge in enablement could entail requires a critical consideration of knowledge. Both the third sector and the HEI partners need knowledge and novel ideas to solve complex problems in society and enable people, institutions and communities to change conditions in their everyday world (Filstad \& McManus 2011:764). Thus the problem solving process implies change and the product of problem solving usually results in change. Change is also fundamental to innovation (Brown 2010:1212). Problem solving is found at the heart of the research process and the outcome of research is then the creation of new knowledge, as novel ways to solve the problem are unearthed. One such example of innovation is found in Elene Cloete's, chapter where she used social network analysis to shed an alternative light on the relations and degree of interaction between third sector and higher education institutions. In so doing she contributed to gaining a deeper understanding of partnership dynamics.

It is vital that the research needs to be appropriate for the context and include direct social change (Chen, Jones \& Gelberg 2006:118). Furthermore, it should involve both the community and academic partners. The development of academics, students and external participants as knowledge brokers is important. Some of them would occupy positions of dual membership of the systems. Others will have to 
possess and further develop the ability to practise "compassionate imagining" (Waghid 2009:77-80) through regular interaction with participants of the 'other' system. This requires that they go on to imagine how the knowledges can be incorporated into the curriculum and in working towards the achievement of goals in the third sector and the communities that they interact with. How complex the role of a boundary (knowledge) worker can be, is highlighted by McMillan (2009), who pleads for more understanding of and support for knowledge brokers from either side as they "need to have the confidence and courage to transgress into the knowledge of the other community, and to manage this transgression" (McMillan 2009:249). They clearly have a better chance of success if there is an enabling environment with others supporting their efforts. Brew (2003:180) contends that an integrated view of academic work as "inclusive knowledge-building communities of practice" is relevant. This type of research focuses on the involvement of all partners in the creation of knowledge to solve relevant problems (Wright et al 2011:83). The community-engaged scholarship (CES) or community-based research (CBR) approach to inquiry has been proposed by authors such as Freire and Fals-Borda (Minkler 2004:686) to "counter the 'colonizing' nature of research" often found in community education attempts. Petersen and Osman (2013:17) agree and refer to the traditional hegemonic position and dominance of academic knowledge; they note that the university not only "defines and constructs knowledge" but should also engage with "knowledge created in other sites of practice". In addition, Hall (2009:5) suggests that engagement pushes at the "boundaries of conventional knowledge-making".

Concepts commonly referred to in community engagement and CBR (such as participation, enablement, collaboration and empowerment) often vary across contexts and sites and depend on the positions and relationships within the sites and systems. They are thus likely to be relative and vary as the conditions change considerably from one context to another (McKenna \& Main 2013:114). The nature of the project is that new knowledge to deal with a [community] issue is mutually constructed from both community [third sector] and academic components. Furthermore, there is an impact on the academic curriculum as it is re-examined in the light of [community-based] learning (Garraway 2009:244 - 'work' substituted with 'community').

Chen et al (2006:119) note the implications of CBR methods for design and practice, and ultimately ethics, and Minkler (2004:686) warns that in using a community-based approach to research it is important to guard against research which is "community placed" and not "community based". This difference has an 
influence on the attitude of the role-players, and if participation and ownership are not hallmarks of interaction, then the sustainability of these projects is questionable. The complexities of ethical considerations and the implications for practice are the main focus of the chapter by Sunette Pienaar. She notes that partners in community projects are often unprepared to deal with the challenges presented by collaboration and partnerships. She proposes an ethics framework, which might contribute to enabling participatory knowledge sharing among different sectors. In what could be regarded as an extension of this ethics framework, Karen Venter and lelse Seale offer a framework of principles to guide the reciprocal knowledge sharing process among service learning participants. The focus of their empirical study was on establishing what service learning champions from the various sectors regarded as prerequisites for truly enabling knowledge sharing.

In discovering a common focus, the current debate around survival in the global world has relevance to all systems in society. In this regard James et al (2013:246) refer to the importance of knowledge, innovation and creativity for survival. The link to knowledge for enablement thus applies. Creativity in this context refers to the development of novel and useful ideas (Liu, Liao \& Lio 2012:1188) and is the expected outcome of formal research qualifications (Frick 2012:125). Thus creative problem solving for change through research processes could be the basis for survival and optimal development when referring to the community engagement projects in higher education. Chen et al (2006:120) argue that usefulness is an important notion when discussing reciprocity between the third sector and higher education. One such example of usefulness is reported in Elanie Myburgh's chapter on harnessing technology in the development of a knowledge sharing and communication platform for partners across sectors. The platform, in the form of a learning management system, provided an inclusive environment for all participants and the participants reported feeling more empowered because they had a more equal voice and were able to share their views openly with all participants. James et al (2013:249) refer to the innovation which is characterised by knowledge interactions. Knowledge for enablement therefore needs to contribute to useful, creative and novel solutions to complex problems in communities. If all partners are united in the quest for creative solutions, and not merely driven by the imperatives and directives through policy documents and mission statements, then intrinsic engagement will provide fruitful focus in the knowledge as enablement project. 


\section{THE PROCESS TO FACILITATE CHANGE FOR KNOWLEDGE ENABLEMENT}

Facilitation of the process of knowledge enablement may be needed when working with higher education-third sector partnerships. The type and level of change is important as it influences the sustainability and level of engagement in the endeavour. The importance of facilitation is especially pertinent in the complex, fastchanging environment in which universities and communities are based. McWilliam (2013:xvii) asserts that the "habits of deep and sustained engagement in learning (and unlearning)" are vital for participation in this complex environment. For sustained development in this context Guile and Griffiths (2001) state that greater depth of learning, rather than just the specifics of practice or superficial solving of problems, may be needed. This process leads to change or transformation (Mezirow 2000:131). Kolb's (1984) experiential learning theory suggests that learning is a process whereby knowledge is created from a combination of grasping and transforming experiences. Change is thus integral to the process.

There is, however, often an aversion to change and challenge, as contended by McWilliam (2013:vii). In addition, Maskell and Malmberg (2007:606) suggest that the lack of unlearning is often linked to resistance to change. Sometimes change needs to be mediated when there is resistance, so as to break through the established routines where individuals, institutions and communities at times prefer to operate. Resistance may be situated in any of the sites within a system, like the individuals in third sector sites or individuals in the university systems. Mediation was the basis of the learning theory of Vygotsky (1978), who argued that learning takes place between the subject and object via a mediated act (Engeström 2001:134). In the South African service learning context, McMillan (2009:50) refers to the agents who help participants by making new connections across activity systems and in so doing facilitate new learning. McMillan (2009:57) highlights the importance of a shift from individualised practice to social practices between constituencies. Her view echoes that of Bartlett and Elliott (2008:66), who suggest that social engagements often engender contexts appropriate for valuable change and learning. Therefore, in the mediation process for change, learning becomes relevant whether it be learning or unlearning (McWilliam 2013:xviii), affecting both the third sector and higher education. In noting the importance of holding on to a common meaning when differences arise, Carlisle (2004:559) states that developing this common meaning is a "process of negotiating and defining common interests".

Cognisance of the relationships where reciprocal benefits are valued is pivotal to sustainable knowledge enablement. Filtstad and McManus (2011:767) confirm the relational dimension of change in the learning process. Edwards (2011:33) 
gives an interesting perspective in her research, and she refers to professionals in a collaborative work setting where both parties recognise distinctive expertise that varies across settings and contexts. These partners bring relational expertise together with their individual expertise, which enriches and enhances responses in an intervention. In addition she notes that relational agency is the capacity to work with others to "strengthen purposeful responses to complex problems" (Edwards 2011:34). Pulane Pitso's chapter emphasises the value of authentic dialogue in collaboration efforts and demonstrates how she included the voice of the third sector in the context of the quest for improved service delivery in South Africa.

The mutual learning perspective is reflected in the work of James et al (2013:250), who state that learning is interactive and territorially embedded; it is a collective process at the individual and institutional levels and is not only an acquisition of specific technical (component) knowledge but also of routines and informal institutions (what they refer to as "architectural knowledge"). In reference to boundary work in an activity system, Edwards (2011:35) argues that boundaries are social constructions where "practices are alerted to changes which may affect actors' relative power, their resources and their identities". Edwards (in press) refers to the needs for "sensitive reciprocity" in facilitating learning. This not only illustrates the complexity of learning in such an environment but also reflects the "both-ways" process in community engagement.

Creativity may be required to solve complex problems and may be the outcome of organising knowledge in new ways. Hall (2009:11) calls this a "burst of creativity". Often, however, tensions may be present among team members in a creative endeavour (Perez-Freije \& Enkel 2007:11). Participants from both systems perform 'boundary work' that enables the transfer of knowledge across boundaries and its successful hybridisation. Hybrid forums, committees or discussion/working groups could be formed in which heterogeneous participants come together to work on the development of community-third sector-academic hybrid knowledge constructs (Garraway 2009:241-245). It is crucial to take into account their relative positions of power (Petersen \& Osman 2013:12-13, 22). Dysthe, Samara and Westerheim (2006:303) state that dialogism, which sees knowledge as a process and product of interaction, is concerned with developing and transforming understanding through tensions between multiple perspectives and opinions. In this context then, meaning is created in interactions amongst dialogue partners. Filstad and McManus (2011:767) propose that in a complex system, the interconnected parts support and produce each other. Varied individual responses to collective challenges and opportunities therefore result in a continuous process of selection and interactive 
knowledge creation (Maskell \& Malmberg 2007:609). McMillan (2009:57) contends that different knowledges, voices and experiences need to be seen as central to engagement practices. As has been stated above, Edwards (2011:34) refers to relational agency when working together to solve complex problems. She mentions the constant dynamic of experts by recognising the motives and values that others bring to the endeavour and interpreting them in the current context. Furthermore, there is a need to constantly align the individual responses to the new interpretation of others who are working towards the common purpose. In Patrick and Burneline Kaars's chapter they report on an organisation which is based in a typical South African community that is plagued with societal ills. This registered NPO, of which Patrick is the chief executive officer, renders social services and developmental interventions to the community. These authors report on perspectives from the third sector and explore how to share and apply practical and theoretical knowledge and turn it into real change in communities.

\section{CONCLUSION}

A radical shift in attitude and practice may be required of academics in the partnership when conducting community-based research and practising community-engaged scholarship. Community-based participatory approaches break down the barriers between the researcher and the community (Minkler 2004:686) as both partners hold quid pro quo power relations in the process of useful relevant knowledge creation. Worthen (2011:540) contends that learning happens when, due to the dialectical relationships between the parts, the power balances change and new potential for action emerges and is mobilised. Enablement is thus needed at all sites and at all layers of the system, and therefore mediation in this process may be necessary. If the focus can also be placed on the outcome of knowledge production or the "burst of creativity" referred to by Hall (2009:11), it will serve as a motivational pull in navigating the tensions in the process of knowledge creation for enablement.

We have argued that by focusing on the common mission through sensitive identification of what matters to each partner, positive energy could provide the fruitful focus for community engagement projects. This positive energy is located in the unintended side effects of information exchange and the knowledge spillovers or "local buzz", a term coined by Storper and Venerables (Maskell \& Malmberg 2007:607). It is our desire that the chapters in this book will contribute to understanding knowledge enablement in engagement projects and generate this positive energy to help us navigate the higher education community engagement project - not as a compliance with policy directives or moral imperatives (although 


\section{INTRODUCTION・ALBERTYN \& ERASMUS}

this has its place), but out of a positive drive for reciprocally beneficial knowledge as an enablement project which is sustainable and brings about constructive change in society.

\section{REFERENCES}

Albertyn R \& Daniels P. 2009. Research within the context of community engagement. In: E. Bitzer (ed). Higher Education in South Africa: A scholarly look behind the scenes. Stellenbosch: SUN PReSS. 409-428.

Alperstein M. 2007. Getting closer to the community voice in curriculum development An exploration of the possibilities. Education as Change, 11 (3):59-67.

Bartlett BJ \& Elliott SN. 2008. The contributions of educational psychology to school psychology. In: TB Gutkin \& CR Reynolds (eds). The Handbook of School Psychology. 6th Edition. Mahwah, NJ: Lawrence Erlbaum and Associates. 65-83.

Bezuidenhout I \& Erasmus M. 2013. Arguments in favour of service learning in the South African law curriculum. In: R Osman \& N Petersen (eds). Service Learning in South Africa. Cape Town: Oxford University Press Southern Africa. 162-185.

Boyer E. 1990. Scholarship reconsidered. Priorities of the professoriate. Princeton: The Carnegie Foundation for the Advancement of Teaching.

Brew A. 1999. The value of scholarship. Paper read at the HERDSA Annual International Conference, Melbourne, Australia. 12-15 July.

Brown L. 2010. Balancing risk and innovation to improve social work practice. British Journal of Social Work, 40:1211-1228.

Butin DW. 2010. Service-Learning in Theory and Practice: The future of community engagement in higher education. New York: Palgrave Macmillan.

Carlisle PR. 2004. Transferring, Translating, and Transforming: An integrative framework of managing knowledge across boundaries. Organization Science, 15(5):555-568.

Chen DT, Jones L \& Gelberg L. 2006. Ethics of clinical research within a community-academic partnered participatory framework. Ethnicity and Disease, 16:118-134.

Corry O. 2010. Defining and theorizing the third sector. In: R Taylor (ed). Third Sector Research. New York: Springer. 11-20.

Du Plessis C \& Van Dyk A. 2013. Integrating the community voice into service learning: Engaging with communities. In: R Osman \& N Petersen (eds). Service Learning in South Africa. Cape Town: Oxford University Press Southern Africa. 59-84.

Dysthe O, Samara A \& Westerheim K. 2006. Multivoiced supervision of master's students: A case study of alternative supervision practices in higher education. Studies in Higher Education, 31 (3):299-318.

Edwards A. 2011 . Building common knowledge at the boundaries between professional practices: Relational agency and relational expertise in systems of distributed expertise. International Journal of Educational Research, 50:33-39. 
Edwards A. In press. Designing tasks which engage learners with knowledge. In: I Thompson (ed). Task design, subject pedagogy and student engagement. London: Routledge.

Engeström Y. 2001 Expansive learning at work: Toward an activity theoretical reconceptualization. Journal of Work and Education, 14(1):133-134.

Filstad C \& McManus J. 2011 . Transforming knowledge to knowing at work: The experience of newcomers. International Journal of Lifelong Learning, 30(6):763-780.

Frick BL. 2012. Pedagogies for creativity in science doctorates. In: A Lee \& S Danby (eds). Reshaping Doctoral Education: Programs, Pedagogies, Curriculum. London: Routledge. 113-127.

Frick BL, Albertyn RM \& Bitzer EM. 2014. Doctoral risk in higher education. In: E Bitzer, RM Albertyn, BL Frick, BM Grant \& F Kelly (eds). Pushing Boundaries in Postgraduate Supervision. Stellenbosch: SUN PReSS. 53-66.

Garraway J. 2009. Higher education and the world of work. In: E. Bitzer (ed). Higher Education in South Africa: A scholarly look behind the scenes. Stellenbosch: SUN PReSS. 229-252.

Gibbons M, Limoges C, Nowotny H, Schwartzman S, Scott P \& Trow M. 1994. The new production of knowledge: The dynamics of science and research in contemporary societies. London: Sage Publications.

Guile D \& Griffiths T 2001. Learning through work experience. Journal of Education and Work, 14(1):114-131.

Habib A. 2002. Editor's introduction. In: Swilling M \& Russell B (eds). 2002. The size and scope of the non-profit sector in South Africa. Johannesburg: Graduate School of Public and Development Management, University of the Witwatersrand. vii-xii.

Hall M. 2009. Transgressive partnerships: Community engagement in a South African University. Gateways: International Journal of Community Research and Engagement, 2:1-17.

Hall M. 2010. Community engagement in South African higher education. Kagisano, 6:1 -52.

James L, Guile D \& Unwin L. 2013. Learning and innovation in the knowledge based economy: Beyond clusters and qualifications. Journal of Education and Work, 26(3):243-266.

Jansen JD. 2002. Mode 2 knowledge and institutional life: Taking Gibbons on a walk through a South African university. Higher Education, 43:507-521.

Kolb DA. 1984. Experiential learning: Experience as the source of learning and development. Englewood cliffs, NJ: Prentice Hall.

Kraak A. 2004. Discursive tensions in South African higher education, 1990-2002. Journal of Studies in International Education, 8(3):244-280.

Lazarus J, Erasmus M, Hendricks D, Nduna J \& Slamat J. 2008. Embedding community engagement in South African higher education. Education, Citizenship and Social Justice, 3(1):59-85.

Liu D, Liao H \& Loi R. 2012. The dark side of leadership: A three-level investigation of the cascading effect of abusive supervision on employee creativity. Academy of Management Journal, 55(5): $1187-1212$. 


\section{INTRODUCTION・ALBERTYN \& ERASMUS}

Maskell P \& Malmberg A. 2007. Myopia, knowledge development and cluster evolution. Journal of Economics Geography, 7:603-618.

McKenna SA \& Main DS. 2013. The role and influence of key informants in community-engaged research: A critical perspective. Action Research, 11 (2): $113-124$.

McMillan J. 2009. Through an activity lens: Conceptualising service learning as 'boundary work'. Gateways: International Journal of Community Research and Engagement, 2:39-60.

McWilliam E. 2013. Foreword. In: A Lee \& S Danby (eds). Reshaping doctoral education: Programs, Pedagogies, Curriculum. London: Routledge. xxiii-xxvii.

Mezirow J. 2000. Learning as transformation. San Francisco: Jossey-Bass.

Minkler M. 2004. Ethical challenges for the 'outside' researcher in community-based participatory research. Health Education Behaviour, 31 (6):684-697.

Nduna NJ. 2007. The community voice on service-learning: A good practice guide for higher education. Education as Change, 11 (3):69-78.

Nussbaum M. 2001. Upheavals of thought: The intelligence of emotions. Cambridge: Cambridge University Press.

Nzimakwe TI. 2008. South Africa's NGOs and the quest for development. International NGO Journal, 3(5):90-97.

Perez-Freije J \& Enkel E. 2007. Creative tension in the innovation process: How to support the right capabilities. European Management Journal, 25(1):11-24.

Petersen N \& Osman R. 2013. An introduction to service learning in South Africa. In: R Osman \& N Petersen (eds). Service Learning in South Africa. Cape Town: Oxford University Press Southern Africa. 2-32.

Ridley-Duff R. 2008. The future of business: What is social enterprise? [Retrieved 10 April 2014] http://voices.yahoo.com/the-future-business-1410645.html

RSA DHET (Republic of South Africa: Department of Higher Education and Training). 2013. White Paper for Post-School Education and Training: Building an expanded, effective and integrated post-school system. Pretoria: DHET.

RSA DoSD (Republic of South Africa: Department of Social Development). 1997. Nonprofit Organisations Act 71 of 1997. Pretoria: Government Printing Works.

Swilling M \& Russell B. 2002. The size and scope of the non-profit sector in South Africa. Johannesburg: Graduate School of Public and Development Management, University of the Witwatersrand.

Taylor R. 2010. Moving beyond empirical theory. In: R Taylor (ed). Third Sector Research. New York: Springer. 1-9.

Thomson AM, Smith-Tolken A, Naidoo A \& Bringle R. 2008. Service learning and community engagement: A cross-cultural perspective. Working Paper Series, International Society for Third-Sector Research. Eighth International Conference, Barcelona, Spain, July 9-12. 
UFS (University of the Free State). 2006. Community Service Policy of the University of the Free State. Bloemfontein, South Africa. [Retrieved 10 April 2014] http://supportservices.ufs. ac.za/dl/userfiles/Documents/00000/357_eng.pdf

Waghid Y. 2009. Universities and public goods: In defence of democratic deliberation, compassionate imagining and cosmopolitan justice. In: E Bitzer (ed). Higher Education in South Africa: A scholarly look behind the scenes. Stellenbosch: SUN PReSS. 71-83.

Worthen H. 2011 . CHAT learning theory for labour educators: Work process knowledge, activity theory and communities of practice. Labour Studies Journal, 36(4):538-544.

Wright KN, Williams P, Wright S, Lieber E, Carrasco SR \& Gedjeyan H. 2011 : Ties that bind. Gateways: International Journal of Community Research and Engagement, 4:83-99. 